\title{
O outro avança sobre mim: dimensões da vida anônima e impessoal na cultura latino-americana
}

Florencia Garramuño ${ }^{1}$

O título deste trabalho - "O outro avança sobre mim" - é inspirado em uma frase, levemente diferente, de O inominável, de Samuel Beckett, último romance da trilogia impessoal com a qual Beckett abalou de modo contundente a ideia do romance concentrado na personalidade e no indivíduo. Livro radical na abstração e despojamento do eu de toda característica e categoria definidora, $O$ inominável é, todavia, um livro sobre o eu, uma reflexão sobre o estado da ficção europeia no pósguerra e um romance que, na desapropriação de todo traço de pertencimento a uma especificidade, realiza, no terreno da narrativa contemporânea, uma intervenção certeira - das mais radicais - sobre a dificuldade de escrever romances, ali, onde a autonomia da experiência subjetiva tem sido posta em questão (Hansen, 2009, p. 16). ${ }^{2}$

Não falarei neste texto de Beckett, mas a frase me interessa, porque parece condensar a problemática emergente em algumas práticas contemporâneas que apontam para uma desconstrução da categoria de pessoa explorando formas do impessoal ou anônimo que insistem em interrogar a intensidade de uma vida que é irredutível a um eu e ao indivíduo. Nessas práticas, as noções de sujeito, de indivíduo e de subjetividade - tanto como a própria noção de uma experiência que apareceria atrelada a essas noções - parecem ter sido substituídas por figuras diferentes, irredutíveis à noção de indivíduo e sujeito. Em textos, performances, filmes, obras dramáticas, poemas e algumas das instalações que mais me interpelaram nos últimos anos, alguma coisa foge das constrições da identidade e arrasta a produção e a prática a

\footnotetext{
${ }^{1}$ Doutora em Línguas e Literaturas Românicas, professora da Universidad de San Andrés, Buenos Aires, Argentina. E-mail: florg@udesa.edu.ar

${ }^{2}$ Sobre esse texto, assinala Hansen: "O inominável é um magnífico romance de reflexão escrito como essa ab-extração. Não como os tradicionais, em que a reflexão é orientada por um sentido que a faz tomar partido disso ou daquilo. Em Beckett, a experiência do tempo não tem finalidade. Como Molloy, como Mallone morre, $O$ inominável é um romance de reflexão sobre o estado da ficção e da arte na realidade do pós-guerra em 1948. Reflexão sobre a impossibilidade de escrever romances relatando coisas vividas por indivíduos exemplarmente positivos como heróis de alguma causa, ou negativos, como anti-heróis de algum problema. Impossível haver histórias assim num mundo em que a morte industrial de milhões foi continuação do que já se fazia na paz: a transformação de todas as relações humanas em cifras que tornam irrelevante a autonomia da experiência subjetiva" (Hansen, 2009, p. 16).
} 
formas mutantes e instáveis, que surgem em constante ebulição, e parece se sustentar precisamente na impossibilidade de encontrar um único indivíduo ou uma única experiência que seria a origem ou o alicerce para a elaboração que empreendem tais práticas. Como se elas interrogassem não uma vida nem uma história particular, mas a vida como força impessoal, que, se por momentos precisa se concretizar numa narrativa relato sobre um sujeito, o faz de um modo que este só implica o espaço em que se afirma uma vida irredutível à forma individual. Nessa irredutibilidade da vida à forma individual, a trama de relações nas quais se manifesta uma vida impessoal adquire protagonismo para definir, num entorno de afetos e relações, mais que o desenvolvimento de uma subjetividade ou a noção de um grupo ou coletivo entendido sob a ideia de uma identidade compartilhada, $o$ espaço intervalar entre coisas e entre seres. ${ }^{3}$ Não se trata de identificar um grupo ou expor o povo ou alguma entidade coletiva - os marginais, os desprotegidos (muito embora muitas vezes seja sobre esses corpos que são exploradas as relações) -, mas de diagramar o espaço de uma relação; daí a importância que adquire nessas narrativas e práticas a exposição do afeto - em detrimento, por exemplo, do desenvolvimento de uma personalidade. Trata-se de pensar a vida como aquilo que se opõe ao eu, para além da consciência, da memória e da identidade pessoal; trata-se de pensar a vida que se desdobra segundo uma lógica que já não segue o desenvolvimento de uma interioridade, mas a exposição de um ser em comum. ${ }^{4}$

\footnotetext{
${ }^{3}$ Segundo Gabriel Giorgi em Formas comunes, é a partir dos anos de 1970 que a literatura começa a registrar "escrituras que nascem da verificação de que a vida já não pode ser resumida ou contida no formato do indivíduo: como se a cultura tivesse descoberto que a noção de "vida própria" se tornou insustentável, e por isso necessitaria elaborar outros modos de registro, captura, percepção e reflexão sobre o vivido" (Giorgi, 2014, p. 37-38, tradução nossa).

${ }^{4}$ Em sua introdução à Pure imanence: essays on a life, de Gilles Deleuze, John Rajchman discorre sobre o conceito de vida em Deleuze: "Poderíamos pensar a vida como um conceito empiricista em contraste com o que John Locke definiu como o indivíduo. A vida tem características muito diferentes das que Locke associou com o indivíduo - consciência, memória e identidade pessoal. Ela se abre segundo uma outra lógica" (Rajchman, 2001, p. 8, tradução nossa). Roberto Esposito tem trabalhado no mesmo sentido de tentar capturar o conceito de uma vida para além do sujeito. Discutindo a categoria de pessoa e sua intrincada relação com o impessoal, Esposito realizou uma exaustiva genealogia de um pensamento sobre o conceito de impessoal que Foucault e Deleuze desenvolveram em diversos modos de conceitualizar a vida. Diz Esposito: "Pode-se dizer que, para Foucault, a vida é o estrato biológico que não coincide nunca com a subjetividade, porque está sempre pressa a um processo, duplo e simultâneo, de submissão e subjetivação: espaço sobre o qual o poder investe sempre sem conseguir nunca ocupá-lo totalmente, gerando, inclusive, formas sempre renovadas de resistência. Diferente, ainda que orientada para o mesmo resultado, é a direção que adota Deleuze. Não é a da exteriorização mas a da retração [...]. É difícil, para uma
} 
Refiro-me a textos como Mano de obra, de Diamela Eltit, concentrado na vida dos trabalhadores de um supermercado no Chile neoliberal, que rejeita a todo momento se constituir como a narrativa de uma comunidade homogênea, insistindo, pelo contrário, em uma despersonalização radical de narrador e personagens. Penso também em trabalhos fotográficos como Marcados, de Claudia Andujar, ou Zona Sur - Barrio Piedrabuena, de Gian Paolo Minelli, em que a sobrevivência de duas das mais ricas tradições na exibição do rosto dos povos - a da fotografia documental e a do retrato - permitem explorar o modo como alguns dispositivos da fotografia contemporânea articulam um discurso que exibe o ser em comum de algumas comunidades. Como elas, várias intervenções recentes na cultura latino-americana desenham figuras diversas do impessoal, que fazem com que emerja a potência de uma vida sem individualidade.

Entre os textos e trabalhos que formam parte desta proposta incluem-se, por um lado, textos escritos como escuta de várias vozes diferentes sem identificação do sujeito emissor (como Delírio de Damasco, de Veronica Stigger); por outro lado, tem-se textos que descentram a narrativa a partir de uma multiplicidade de registros (entre o ensaio, o comentário crítico, o testemunho e a ficção), como em História natural da ditadura, de Teixeira Coelho, ou El desperdicio, de Matilde Sánchez, que parecem levar a forma narrativa a explorar outros modos de organização que se desentendem do romance.

Em seu livro A preparação do romance, Roland Barthes se perguntava em 1978- se o romance, enquanto forma, não se deveria considerar obsoleto. Não foi o único - e houve outros ainda antes de Barthes - a assinalar a inadequação de uma forma que nasceu com a modernidade para narrar as transformações radicais a que o mundo contemporâneo teria submetido o sujeito, as relações interpessoais, as noções de espaço e tempo, a experiência.

Quando Walter Benjamin, vários anos antes, ao resenhar o romance Berlin Alexanderplatz, de Alfred Döblin, falava na crise do romance, ele

tradição como a nossa, embebida desde suas origens em teologia política, privar a categoria de decisão de sua conexão com as de indivíduo e soberania - conjugá-la, antes que com a pessoa, com o impessoal. No entanto, é exatamente isso que faz Deleuze, por meio de uma teoria da virtualidade que, rompendo com a alternativa ou coincidência metafísica do possível e necessário, abre a identidade ao jogo plural das diferenças (Esposito, 2009, p. 31-32, tradução nossa). 
se referia a certa concorrência entre o romance, sustentado num puro presente oposto à épica, e a narração pura, mais concentrada na épica que na noção de indivíduo. Dizia Benjamin:

É isso que o distingue (o romance), sobretudo, da narração, que representa a mais pura essência épica na tradição da prosa. Nada contribui tanto para o emudecimento do homem interior, nada modifica mais radicalmente o espírito da narração do que a desmesurada expansão que adquire em nossa existência a leitura de romances. É por isso que a voz do narrador nato se levanta contra a do romancista (Benjamin, 1930, p. 300, tradução nossa).

Se, por um lado, é verdade que, enquanto forma, o romance tem estado sempre em mutação, em transformação, em formação, por outro, nos últimos anos essas transformações têm atingido um grau de expansão que talvez já não possa ser contido na possibilidade cada vez mais ampla de se definir uma forma instável. O certo é que muitos dos textos mais contemporâneos, por uma ou outra razão, já não parecem se acomodar confortavelmente num gênero e, certamente, muito menos se definir pela mera justaposição ou hibridação de gêneros diferentes. Se considerarmos as formas narrativas não a partir de um ponto de vista autônomo ou específico, mas como dispositivos que permitem explorar o mundo e, por sua vez, imaginar mundos possíveis a partir das condições de possibilidade que essas formas tornam visíveis, podemos pensar que as transformações das formas de narração podem iluminar algumas zonas das transformações históricas às quais estas formas tentam dar sentido.

Por seu turno, também na arte contemporânea, algumas intervenções radicais apontam para uma desconstrução da categoria de pessoa ou de subjetividade que exploram formas do impessoal ou do anônimo. Em muitas instalações e séries fotográficas de Rosângela Rennó, Gian Paolo Minelli y Claudia Andujar, o retrato despido de seu culto à personalidade, os enquadres e desenquadres de cidades e de espaços, o relevamento de lugares e a montagem documental ou, ainda, o entrecruzamento entre a fotografia documental e a fotografia conceitual permitem pensar esses ensaios fotográficos como dispositivos para a exibição de uma singularidade plural que discute noções de povo e de comunidade. ${ }^{5}$

\footnotetext{
${ }^{5}$ Sobre a ideia de singularidade plural, ver Being singular plural, de Jean-Luc Nancy (2000).
} 
Como em Nostalgia de la luz, de Patricio Guzmán, ou em O som ao redor, de Kleber Mendonça Filho, interessa-me também incluir nesta proposta filmes nos quais o trabalho em arquivos, a montagem documental e a construção com registro de vozes incomensuráveis descentram as histórias das pessoas e dos indivíduos e superpõem tempos históricos em busca de uma história na qual emerge "a vida impessoal, e no entanto singular, que se desprende de seu puro acontecimento" (Deleuze, 2001, p. 28).

Sustentado na análise de materiais heterogêneos, este texto aspira construir um marco de leitura para uma série de práticas culturais latino-americanas que têm colocado em discussão formas de exploração de noções contemporâneas relacionadas à imaginação, à comunidade, ao "viver junto" (Barthes, 2005) e à subjetividade.

Como é configurado esse interesse pela vida anônima? Por que o interesse por ela tem se intensificado, e como devem as práticas estéticas se modificar para dar conta dela? Como reagem a arte e a estética perante uma perda de densidade do sujeito e da experiência? Quais são as potencialidades e, por outro lado, os problemas de um pensamento sobre o impessoal?

Nas práticas que são objeto deste trabalho, as figuras que vêm substituir a ideia de um sujeito ou de um indivíduo com suas características pessoais, ou a ideia de uma experiência coletiva definida com contornos identificáveis, não adotam a mesma forma nem se constroem com dispositivos necessariamente semelhantes. Mas, em geral, em todas elas, trata-se de uma substituição da categoria de indivíduo ou sujeito, bem como de entidades coletivas como povo ou massa, por uma série de figuras e vozes que, apesar de reterem uma ideia de singularidade, não costumam se reduzir à construção de identidades pessoais ou individuais.

Roberto Esposito tem trabalhado - tanto em Tercera persona como em El dispositivo de la persona - no que ele identifica como um esgotamento da categoria de persona, que, ainda que possa deslocar e redefinir os umbrais segundo os quais separa os homens dos seres humanos, não pode nunca suprimi-los; não pode reparar "o extraordinário hiato entre vida e direito, entre nomos e bios, porque é ela mesma a que o produziu (Esposito, 2009, 
p. 59, tradução nossa)" ${ }^{6}$ Perseguir os modos como as práticas culturais registram esse esgotamento, por um lado, e mapear as novas figuras com as quais elas empurram esses vazios para fora de suas preocupações, por outro lado, propõe-se como um modo de interpelar a produção estética contemporânea para reconhecer nela outros modos de imaginar a organização da experiência e da comunidade.

Gostaria apenas de percorrer algumas dessas práticas e apresentar, de modo experimental, as potencialidades que elas abrem para um pensamento acerca de problemas contemporâneos.

\section{Mano de obra, de Diamela Eltit e a potência da despersonalização}

Em Mano de obra, um texto publicado em plena implantação furiosa do neoliberalismo chileno (2000), Diamela Eltit trabalha uma desconstrução radical da categoria de persona que - entre outras estratégias - conduz a uma forte desestruturação da forma romance. $\mathrm{O}$ texto narra - de modo fragmentário e entrecortado, isto é, com uma trama debilitada ao extremo para deixar emergir a cada instante a intensidade dos afetos - a vida anônima dos trabalhadores de um supermercado. Para isso, desestima o uso da terceira pessoa e se dirige rumo à composição de uma sorte de colagem de diferentes perspectivas narrativas, nenhuma das quais acaba por se aderir a uma noção estável de pessoa.

A primeira parte do romance coloca-se no espaço do supermercado e está constituída por uma série de vinhetas narradas, em primeira pessoa, por um trabalhador de supermercado despojado de todo traço de identidade - além de sua condição laboral. Apesar de ser constante em todas as vinhetas, essa primeira pessoa poderia se referir, na verdade, a vários trabalhadores diferentes, já que nada a identifica nem a conecta a um único personagem ou narrador. Reduzido à sua

\footnotetext{
${ }^{6}$ Um pouco antes, o autor afirma: "Se não existe um sujeito individual pré-definido em relação às potencias vitais que o atravessam e o constituem; se o sistema do direito, com sua promessa de igual distribuição, só expressa e sanciona, legitimando-o, o resultado, por sua vez transitório, das relações de força derivadas de choques passados; se até a instituição do Estado, tal como é pensada pelos teóricos da soberania, não constitui mais do que a envoltura imunitária destinada a submeter os súditos a uma ordem que às vezes contrasta com seu próprio interesse, quando deveria protegêlos disso; se tudo isto é certo, então, a relação entre os homens está submetida a um processo de radical revisão, que o dicionário político moderno é completamente incapaz de encarar" (Esposito, 2011, p. 36).
} 
condição de trabalhador de supermercado, nada de sua vida pessoal emerge no fluxo da consciência que se cristaliza em um monólogo que tem perdido toda condição pessoal. Carente de marcas de identidade, o narrador incluso reconhece o seu acionar como alguma coisa que está além de sua vontade, desejo ou agência. Diz, por exemplo:

A uma distancia incomensurável de mim mesmo, organizo as maçãs. Já estão se apagando os contornos geométricos nos quais os metais adquirem seu incisivo destino. Estou infectado, atravessado pela debilidade. Este enorme torpor me mantém exausto e vencido ante a impenetrável linearidade das prateleiras. Olho fixamente (muito embora saiba que não devo fazê-lo) as mercadorias e, no entanto, não consigo retê-las nem fazê-las voltar (recuperá-las) para anexálas na memória professional que devo exercitar com os produtos (Eltit, 2002, p. 47, tradução nossa e grifo nosso). ${ }^{7}$

A segunda parte do romance desloca-se do espaço público para o espaço privado de uma casa, onde um grupo de trabalhadores do supermercado compartilha despesas e vida em comum para enfrentar a dificuldade econômica a qual os lança uma flexibilidade laboral sempre ameaçante e um salário que não é suficiente para as despesas mínimas. Nessa segunda parte, o narrador se configura como uma primeira pessoa do plural não inclusiva que, em cada capítulo, exclui só um dos habitantes da casa. Isso permite explorar a ideia de uma voz plural que, no entanto, modifica-se capítulo a capítulo para cristalizar, em cada um deles, o modo em que o personagem que não está incluído essa vez é visto por essa primeira pessoa plural. No exemplo que cito, trata-se de:

Isabel parecia cansada. Assim que entrou em casa nos informou que seu turno no supermercado foi estendido por duas horas. Duas horas a mais de pé, disse, devastaram seu humor. Nós nos punimos. Acompanhamo-la até seu quarto. O bebê já estava dormindo. Isabel nem percebeu. Ajudamo-la a se deitar em sua cama. Observamo-la até que começou a fechar os olhos e, imediatamente, soubemos que Isabel ia acordar, porque dormia agitada. Acordava várias vezes à noite e fazia ruídos inconvenientes. Entrava no banheiro ou percorria a casa sem o menor silêncio. Já tinha se convertido em uma insone. Pouco a

\footnotetext{
${ }^{7}$ Este capítulo tem o título de "Acción Directa", e o subtítulo "Santiago, 1920".
} 
pouco. $\mathrm{O}$ excesso de trabalho do último ano deixou-a nesse estado. "Tensa", disse ela (Eltit, 2002, p. 79, tradução nossa).

Essa primeira pessoa plural mutante faz com que, no texto, todos os personagens apareçam vistos apenas do exterior, completamente despidos de interioridade e autoconsciência, conformando um grupo cambiante e um tanto fantasmagórico, no confim entre sua condição de trabalhador de supermercado e integrante de uma comunidade regida pela necessidade.

Como apontou Héctor Hoyos, em Beyond Bolaño, the global Latin American novel, no livro de Eltit,

o foco não está dirigido para o espaço do supermercado ou os trabalhadores per se, mas num corpo coletivo e amorfo que se aglutina em torno do constructo histórico do supermercado. Os personagens são elementos funcionais de um projeto mais amplo, não mimético, por isso nenhum empregado é também comprador no supermercado, como seria o caso na vida real. Os protagonistas reais são as relações de produção no tempo, vistas pela perspectiva do presente (Hoyos, 2015, p. 104-105, tradução nossa).

Com uma força descentralizadora e despersonalizadora ainda mais violenta, os títulos dos capítulos - se é que ainda queremos chamá-los assim - do romance remetem, num exercício de citação benjaminiana, aos periódicos da imprensa operária chilena da primeira parte do século XX. Verba roja, El despertar de los trabajadores e Puro Chile são alguns dos títulos que, se confrontados com as pequenas estórias dos trabalhadores, parecem dar conta da desaparição do trabalhador como sujeito operário político e da emergência de "uma comunidade precária de indivíduos, cujo horizonte de expectativa é dado pela incerteza e intercambialidade, diante do salário improvável e o emprego incerto" (Blanco, 2006, p. 179, tradução nossa).

Sobre essa colagem apontou Nelly Richard (s.d., tradução nossa):

Passamos do passado de rebeldias e insurreições populares evocados pelos titulares da imprensa operária e sindicalista para um presente de obediências e servilismos que leva o mundo salarial a se comportar como uma simples extensão resignada da prepotência do capital. A proeza proletária que emoldura os capítulos do romance constrói uma relação de alto contraste entre as tramas épicas do passado e as mesquinhas paródias de sobrevivência que acompanham a desproletarização do mundo 
laboral do "super". A transição desesperada entre um mundo e o outro (da mão de obra para a abstração do valor, da luta social para o conformismo de mercado) adquire um fio seco e cortante pelo procedimento técnico da colagem que o romance utiliza em seus títulos. É a brusquidão do corte e da justaposição, sem outra narratividade que a da cisão, a que define a derrota histórica como irremediável.

No entanto, é também evidente que, nas páginas de Mano de obra, organiza-se e desorganiza-se, de modo rizomático, uma comunidade de corpos que, na materialidade de sua fala - de sua voz - e na irredutibilidade de seus corpos, opõem outras formas de subjetivação que fogem dos mecanismos do poder, operando uma saída da representação.

Entre as citações e a lembrança de uma história de lutas que interrompem a narrativa e a figuração de um corpo com seus humores, desejos e instintos, o texto se constrói como uma poderosa articulação de elementos heterogêneos e histórias perdidas dentro de uma única narração (Draper, 2010), conseguindo apartar o trabalhador de sua exclusiva condição de vítima, revelando um tipo de agenciamento que não está sustentado na categoria de indivíduo, e exibindo o potencial de dominação do neoliberalismo sobre corpos e consciências de um modo que talvez não teria sido possível com outra forma narrativa. Mais ainda: essa organização narrativa permite narrar a potência dos trabalhadores mesmo quando o acesso ao poder é negado, bem como narrar dessa maneira a potência de uma vida impessoal que poderá, quem sabe, resistir imaginando novas formas de subjetivação.

\section{A série e o retrato: Claudia Andujar}

O conjunto de fotografias incluídas em Marcados, de Cláudia Andújar, foi exibido pela primeira vez na $27^{a}$ Bienal de São Paulo, em 2006. Recebeu o título "Como viver junto", inspirado nos cursos e seminários - posteriormente transformados em livro - de Roland Barthes no Collège de France. Na esteira das preocupações de Barthes, a bienal - que teve a curadoria de Lisette Lagnado - propôs uma reflexão sobre os modos de coabitar e de construir espaços comuns, reunindo um conjunto de obras diversas e heterogêneas, que elaboraram 
problemas relacionados às diferenças culturais, às migrações, às formas de convivência e às práticas colaborativas (Lagnado, 2006, p. 16). ${ }^{8}$

Menciono essa primeira exibição da série Marcados para situar a interpelação conflitiva que o retrato desses rostos e corpos provoca, bem como a posição ambivalente das fotografias em relação às suas funções e a seus contextos de inscrição. Na tradição da fotografia documental (de August Sander a Walker Evans), as fotografias de Marcados foram tomadas como parte de uma expedição realizada por Andujar e dois médicos para realizar um levantamento da saúde dos Yanomami. Como apontou a fotógrafa, "como os Yanomami não respondem a nome próprio, foi adotado o método consagrado desde o século XIX para a identificação dos chamados povos nativos: uma fotografia com um número preso ao corpo" (Andujar, 2006, p. 50).

Para além da tradição da fotografia documental, ou melhor, precisamente porque essa tradição esteve muito ligada ao uso da fotografia nos primórdios da antropologia, as fotografias de Andújar evocam as fotografias que Claude Lévi-Strauss tirou em suas viagens pelo Brasil. ${ }^{9}$ Assim como as fotografias de Lévi-Strauss, as de Andujar foram também obtidas como parte de uma expedição que procurava observar e estudar uma população e realizou um levantamento do território e da população. Levantamento que, no caso de Andujar, e no momento em que ela produziu essas fotografias (1981-1983), já levava vários anos, visto que desde 1970 a fotógrafa já realizava expedições ao Amazonas para fotografar as populações daquela região. Na exibição da Bienal, as fotografias eram acompanhadas de documentos que as contextualizavam nesse levantamento, como o "Informe 82" (1982), elaborado pela Comissão Pró-Yanomami (CCPY), presidida pela própria Claudia Andujar. As fotografias se inscrevem, assim, num contexto denso, no qual o trabalho de ajuda para a sobrevivência dos Yanomami e a fascinação por seu mundo emergem em retratos com uma capacidade impressionante de interpelação.

\footnotetext{
${ }^{8}$ Com o título Marked for life, marked for death, uma instalação com três destas fotografias foi apresentada em Londres, em 2005, durante a exposição "Citizens", na Pthsanger Mannor Gallery and House (Senra, 2009, p. 134).

${ }^{9}$ Em Light in the dark room: photography and loss, Jay Prosser (2004) lembra que antropologia e fotografia foram inventadas simultaneamente e imediatamente conectadas: "Ambas as formas foram inicialmente concebidas como modos de observar e documentar a realidade. Os antropólogos abraçaram a fotografia por sua aparente capacidade de mostrar o seu referente de modo não mediado".
} 
No caso das fotografias de Andujar em Marcados, trata-se de retratos. Considerando a combinação de fotografias de grupos, retratos de pessoas e fotografias de paisagens ou de sujeitos em suas ações e costumes cotidianos - o tipo de fotografias que costumam acompanhar as expedições antropológicas e que, de fato, integram Saudades do Brasil -, Marcados está constituído exclusivamente por 82 retratos de pessoas, retiradas de suas ações habituais. Só em alguns poucos casos aparecem as mães com seus bebês ou meninos pequenos. A utilização de uma série de procedimentos formais semelhantes em todas as fotografias organiza os retratos: o uso das placas com o número, o tipo de enquadre e a iluminação reúnem as 82 fotografias em uma mesma série.

Quero sublinhar o uso do retrato - e não outro tipo de fotografia de pessoas ou de grupos, ou coletivos - para retratar os Yanomami na série de Andujar. Se o retrato é a fotografia que outorga poder soberano aos rostos, é evidente que aqui esse poder se sustenta num uso muito particular e consciente dessa tradição (Didi-Huberman, 2015).

Aliás, é no jogo entre a série e o retrato que gostaria de me concentrar nesta análise. Entre a densa trama de operações e dispositivos que constroem essas fotografias, é entre a série e o retrato que se cria a capacidade de encarar de volta - de retornar o olhar - do retratado, e um modo de interpelação que, ao mesmo tempo que se sustenta nessa capacidade de olhar, recusa a individualização personalista do retrato mais tradicional.

Nessas fotografias, o dispositivo do retrato se conjuga com um uso da série que descentra a individuação de um modo bastante evidente. Em primeiro lugar, muito embora se trate, em todos os casos, de retratos, por um lado, cada fotografia varia levemente o enquadramento para valorizar alguns traços pessoais ou detalhes da vestimenta ou da postura. No entanto, a mesma vestimenta que identificaria a alguns dos Yanomami é utilizada por outro, como se pode perceber no caso do vestido de duas meninas. Por outro lado, também as poses dos retratados variam radicalmente em alguns casos. Enquanto alguns - em geral, crianças - olham com certo temor para a câmera, outros lançam um olhar desafiante ou até riem diante da câmera, sustentando um olhar enigmático. É também evidente o jogo que se produz ao confrontar as fotografias dos Yanomami ${ }^{10}$ que aparecem vestidos com

\footnotetext{
${ }^{10}$ Os que, por sua localização geográfica, têm tido um contato maior com os "brancos".
} 
as dos que aparecem nus, usando apenas seus ornamentos tradicionais (Senra, 2009, p. 134). Se o retrato fotográfico reconhece sua origem na fotografia de identificação - aquela para a qual uma mesma pose e uma mesma iluminação normatizam o gênero fotográfico -, nos retratos de Andujar, o uso diferenciado das poses e da iluminação singulariza cada uma das pessoas retratadas, criando uma modulação entre a tradição da fotografia de identificação e o retrato. No entanto, como apontou Stella Senra, pode-se dizer que

não há propriamente "sujeitos" diante de sua câmera, e tampouco uma suposta "interioridade" pronta a ser descoberta; ali, na grande maioria das vezes, não há sequer "rostos" - essa premissa é condição para a existência do retrato fotográfico. Mas, em lugar de tomar tal ausência como falta, a fotografa faz dela mesma o objeto de suas fotos, buscando mostrar, por meio dessa espécie de "descompasso", como cada um dos índios se comporta diante da nova situação - ou seja, como os Yanomami "adquirem" um "rosto" e como "se tornam" retratos. Ao mesmo tempo, essa "busca" do retrato lhe permite tomar a própria fotografia como um operador do contato, como um elemento exterior ao mundo dos índios, com o qual eles têm de se defrontar (Senra, 2009, p. 135).

Interessa-me, especialmente, essa ambivalência entre a individualização que permite o retrato e o descentramento simultâneo do pessoal e da identificação que permite a série com suas leves variações, porque nela se conjugam as potencialidades de um pensamento que vai para além da identidade dos sujeitos - sejam eles concebidos em termos individuais, sejam constituindo um coletivo mais amplo - que é possível destacar nessas fotografias. ${ }^{11}$

Se, aliás, lemos esses jogos junto com o enquadramento que proporcionam às fotografias os textos de Andujar incluídos no começo do livro, a potência dessas saídas do pessoal para encontrar outros modos de organização dos seres que propicie uma solidariedade ampla e transversal parece evidente. Trata-se de três textos nos quais Andujar relaciona os números dos Yanomamis com os números utilizados pelo

\footnotetext{
${ }^{11}$ Pode-se dizer que essas fotografias evidenciam o questionamento que Jean-Luc Nancy propõe para o retrato em La mirada del retrato. Segundo Nancy, o retrato põe em jogo a ambivalência do sujeito, em que emerge a gênese sempre inacabada que o estrutura, socavando-o (Nancy, 2006).
} 
regime nazista para marcar os judeus. O primeiro texto coloca no lugar do título a data 1944 e inicia-se com as seguintes palavras:

Aos treze anos tive o primeiro encontro com os "marcados para morrer". Foi na Transilvânia, Hungria, no fim da Segunda Guerra. Meu pai, meus parentes paternos, meus amigos de escola, todos com a estrela de Davi, visível, amarela, costurada na roupa, na altura do peito, para identificá-los como "marcados", para agredi-los, incomodá-los e, posteriormente, deportá-los aos campos de extermínio (Andujar, 2009, p. 4).

Andujar relata, então, sua primeira relação amorosa com um desses "marcados": o Gyuri, um colega da escola.

O segundo texto de Andujar coloca no mesmo lugar do título a data de 1980 e explica os motivos da expedição que deu origem às fotografias dos Yanomami. Sobre elas, diz Andujar:

São as circunstâncias desse trabalho que pretendo mostrar por meio destas imagens feitas na época. Não se trata de justificar a marca colocada em seu peito, mas de explicitar que ela se refere a um terreno sensível, ambíguo, que pode suscitar constrangimento e dor. A mesma dor que senti por amor ao pisar na grama do parque, um amor impossível com Gyuri. Ele morreu em Auschwitz naquele mesmo ano de 1944 (Andujar, 2009, p. 5).

Entre um e outro texto resulta evidente a superposição de populações e de tempos, a latência da história e a conexão dos dispositivos de individuação, bem como a ambivalência que os mesmos propiciam. O último texto, “2008”, termina com as seguintes palavras:

É esse sentimento ambíguo que me leva, sessenta anos mais tarde, a transformar o simples registro dos Yanomami na condição de "gente" - marcada para viver - em obra que questiona o método de rotular seres para fins diversos. Vejo hoje esse trabalho, esforço objetivo de ordenar e identificar uma população sob risco de extinção, como algo na fronteira de uma obra conceitual (Andujar, 2009, p. 5). ${ }^{12}$

\footnotetext{
12 "Sem dúvida, minha fotografia é marcada pelo meu passado. Um passado de guerra, um passado de minorias. Isso é algo que não só me preocupa, mas me perturba. É parte da minha vida. Me interesso muito pela questão da justiça e das minorias que estão tentando se afirmar no mundo, mas se deparam sempre com um dominador que procura apará-las. Mas existe também um outro lado, que é a estética, o equilíbrio, presente nas minhas imagens. Nem sempre o lado social pode se
} 
Frente à singularidade que proporciona o retrato, as fotografias de Andujar formam parte de um dispositivo amplo e complexo em que a fotografia se torna um operador de contato entre diversidades e faz emergir uma lógica que privilegia a multiplicidade e a contaminação em contraposição à identidade e à discriminação.

\section{A história impessoal: Nostalgia de la luz}

Gostaria de terminar com algumas imagens de Nostalgia de la luz (2010), de Patricio Guzmán. Trata-se de um trabalho em que o famoso documentarista da Batalla de Chile I, II y III, que registrou os preparativos do golpe de Pinochet e filmou o próprio golpe - com imagens do Palacio de la Moneda sendo bombardeado,$-{ }^{13}$ combina estratégias do cinema documentário com uma primeira pessoa lírica que se estende enquanto testemunha de uma problemática. Em Nostalgia de la Luz, Guzmán conecta as pesquisas dos astrônomos no deserto de Atacama - onde o ar é mais transparente e permite uma melhor observação do espaço - com a memória de outros momentos e experiências acontecidas nesse mesmo deserto. Além do ar, a salinidade do solo conserva muito bem os restos de corpos e objetos. É por isso que também no deserto de Atacama trabalham os arqueólogos que, invertendo a observação dos astrônomos, que se voltam para o céu, recuperam do solo restos das populações indígenas que passaram pelo deserto em suas rotas de migrações. A poucos quilômetros do observatório, durante o século XIX, instalou-se uma mina de cobre, cujas barracas - hoje espectrais - acolheram durante os anos 1970 detidos do regime de Pinochet. Em outra zona do deserto, não longe dali, esse mesmo regime espalhou os ossos dos mortos desaparecidos, que, posteriormente, no final da ditadura, foram retirados clandestinamente. Ali também as mulheres de Calama buscam, ainda hoje - e há mais de 20 anos -, os ossos de seus parentes desaparecidos. Entre a busca dos ossos e a pesquisa das estrelas, o filme força uma analogia - uma outra forma da conexão - a partir do cálcio: o mesmo material que compartilham ossos e estrelas.

juntar ao lado estético. Eu sofro por isso. Quando consigo juntar as duas coisas, me sinto aliviada" (Andujar, 2000, p. 15).

${ }^{13}$ Disponível em: <https://www.youtube.com/watch?v=W-1LZ9L6dhQ>. 
Entre ossos e estrelas, o universo serve como marco para uma reflexão sustentada numa história que, na experiência de uma filha de desaparecidos que se torna astrônoma, cifra enigmaticamente a possibilidade de pensar a história para além dos sujeitos.

Entre a história de Agustina, e a partir da montagem de fotografias de arquivo e imagens contemporâneas, na superposição de entrevistas e reportagens com investigação e imagens de uma poesia inusitada, Nostalgia de la Luz nos impulsa a imaginar uma história impessoal em que possam, no entanto, ser recuperadas - e recordadas - as singularidades da memória. A partir desses dispositivos, o filme parece imaginar novas formas de solidariedade e outros modos de compreender a história - muito benjaminianos, por certo e, sem dúvida, também muito problemáticos.

Discutindo a recente preocupação da filosofia política pela estética, Didi-Huberman aponta:

Nossa maneira de imaginar consiste fundamentalmente numa condição para nossa maneira de fazer política. A imaginação é política, isso é o que é preciso assumir. Por seu turno, a política não pode prescindir, em um ou outro momento, da faculdade de imaginação [...] e não devemos nos espantar de que a longa reflexão política empreendida por Rancière tenha tido de se concentrar, num momento crucial de seu desenvolvimento, sobre questões relacionadas à imagem, à imaginação e à partilha do sensível (Didi-Huberman, 2014, p. 46, tradução nossa).

É em função dessa ideia de imaginação que esta proposta buscou analisar os caminhos que, num pensamento sobre o impessoal, essas práticas parecem estar assinalando.

\section{Referências}

ANDUJAR, Claudia (2005). A vulnerabilidade do ser. São Paulo: Cosac Naify.

ANDUJAR, Claudia (2000). Entrevista. In: PERSICHETTI, Simonetta. Imagens da fotografia brasileira. São Paulo: Estação Liberdade; Ed. SENAC.

ANDUJAR, Claudia (2006). Entrevista à Hélouise Costa. In: FUNDAÇÃO BIENAL. $27^{a}$ Bienal de São Paulo. São Paulo.

ANDUJAR, Claudia (2009). Marcados. São Paulo: Cosac Naify. 
BARTHES, Roland (2005). La preparación de la novela. Buenos Aires: Siglo XXI.

BECKETT, Samuel (2009). O inominável. Tradução de Ana Helena Souza. São Paulo: Globo.

BENJAMIN, Walter (2005). The crisis of the novel. In: BENJAMIN, Walter. Walter Benjamin: Selected Writings, Volume 2: Part 1, 1927-1930. Cambridge, Harvard University Press.

BLANCO, Fernando (2006). Poéticas de alienación y muerte en Mano de obra. LLANOS, Bernardita (Ed.). Letras y proclamas: la estética literaria de Diamela Eltit. Santiago: Cuarto Propio, p. 173-200.

DELEUZE, Gilles (2001). Pure imanence: essays on a life. New York: Urzone.

DIDI-HUBERMAN, Georges (2014). Pueblos expuestos, pueblos figurantes. Buenos Aires: Manantial.

DRAPER, Susana (2010). The question of awakeinng in postdictatorship times: reading Walter Benjamin with Diamela Eltit. Discourse, v. 32, n 1, p. 87-116.

ELTIT, Diamela (2002). Mano de obra. Santiago: Seix Barral.

ESPOSITO, Roberto (2009). Tercera persona: política de la vida y filosofía de lo impersonal. Buenos Aires: Amorrortu.

GIORGI, Gabriel (2014). Formas comunes. Buenos Aires: Eterna Cadencia.

HANSEN, João Adolfo (2009). Prefácio. Eu nos faltará sempre. In: BECKETT, Samuel. O inminável. Tradução de Ana Helena Souza. São Paulo: Globo.

HOYOS, Héctor (2015). Beyond Bolaño, the global Latin American novel. New York: Columbia University Press.

LAGNADO, Lisette (2006). Introdução. In: FUNDAÇÃO BIENAL. $27^{a}$ Bienal de São Paulo. São Paulo.

MINELLI, Gian Paolo (2007). Zona Sur. Barrio Piedra Buena. Buenos Aires. Argentina 2001-2006. Geneve: Jean Paul Felley \& Olivier Kaeser.

NANCY, Jean-Luc (2000). Being singular plural. Standford: Standford University Press.

NANCY, Jean-Luc (2006). La mirada del retrato. Buenos Aires, Amorrortu.

PROSSER, Jay (2004). Light in the dark room: photography and loss. Minneapolis: University of Minnesota Press.

RAJCHMAN, John (2001). Introduction. In: DELEUZE, Gilles. Pure imanence: essays on a life. New York: Urzone. 
RICHARD, Nelly (s.d.). Tres recursos de emergencia: las rebeldías populares, el desorden somático y la palabra extrema. Proyecto Patrimonio. Santiago de Chile. On-line. Disponível em: <http://www.letras.s5.com/eltit091202.htm>. Acesso em: 27 fev. 2015.

SENRA, Stella (2009). O último círculo. ANDUJAR, Claudia. Marcados. São Paulo: Cosac Naify, p. 127-142.

Recebido em dezembro de 2015.

Aprovado em fevereiro de 2016.

resumo/abstract/resumen

\section{O outro avança sobre mim: dimensões da vida anônima e impessoal na cultura latino-americana}

Florencia Garramuño

Sustentado na análise de materiais heterogêneos, o texto aspira a construir um marco de leitura para uma série de práticas culturais latino-americanas que pensam a experiência para além do prisma da consciência individual, pensando a vida na sua densidade anônima e impessoal. $O$ trabalho se sustenta na hipótese de que várias transformações sobre os modos de se conceber a subjetividade, a escrita, e a comunidade podem ser apreendidas através de práticas culturais cada vez mais numerosas que registram a transformação de uma paisagem social onde os deslocamentos, o nomadismo e a contingência das relações pessoais são cada vez mais numerosas. Algumas intervenções radicais na cultura latino-americana contemporânea apontam para uma desconstrução da categoria de pessoa que exploram formas do impessoal ou anônimo e insistem em interrogar a intensidade de uma experiência que é irredutível a um eu ou indivíduo. Trabalharemos com textos e práticas de Diamela Eltit, Claudia Andújar, Gian Paolo Minelli e Patricio Guzmán.

Palavras-chave: impessoal, vida, anônimo, contemporâneo.

\section{The other advances towards me: anonimous and impersonal life dimensions in Latin American culture}

\section{Florencia Garramuño}

The article proposes to analyze a series of cultural practices that show different ways to conceive subjectivity, writing and community, registering the transformation of a social landscape where displacements, nomadism and the 
contingency of personal relationships are increasingly more numerous. Some radical interventions in Latin American culture point to a deconstruction of the category of the person and explore forms of the impersonal and the anonymous that interrogate the intensity of an experience that is irreducible to an I or an individual. The text analyzes works by Diamela Eltit, Claudia Andújar, Gian Paolo MInelly and Patricio Guzmán.

Keywords: impersonal, life, anonimous, contemporary.

\section{El otro avanza sobre mí: dimensiones de la vida anónima e impersonal en la cultura de América Latina}

Florencia Garramuño

El trabajo explora la hipótesis de que varias transformaciones sobre los modos de concebir la subjetividad, la escritura y la comunidad pueden ser aprehendidos a través de prácticas culturales cada vez más numerosas que registran la transformación de un paisaje social donde los desplazamientos, el nomadismo y la contingencia de las relaciones personales son cada vez más numerosas. Algunas intervenciones radicales en la cultura latinoamericana señalan una deconstrucción de la categoría de persona y exploran formas de lo impersonal o anónimo que insisten en interrogar la intensidad de una experiencia que es irreductible a un yo o un individuo. Se analizan textos y prácticas de Diamela Eltit, Claudia Andújar, Gian Paolo Minelli y Patricio Guzmán.

Palabras clave: impersonal, vida, anónimo, contemporáneo. 